\title{
Correction to: A spatio-temporal process visualization approach for wind features
}

\author{
Kun Zheng ${ }^{1} \cdot$ Yuyao $\mathrm{Ci}^{1} \cdot$ Hongyu Liu ${ }^{1} \cdot$ Jinbiao Zhang $^{2}$ \\ Published online: 5 September 2021 \\ (C) Springer Nature Switzerland AG 2021

\section{Correction to: Computational Geosciences https://orcid.org/10.1007/s10596-021-10080-z}

The original version of the article unfortunately contained two errors.

1. The address of the author Jinbiao Zhang was wrong. The correct author affiliation is shown below.

Jinbiao Zhang's affiliation:

Guangdong Meteorological Observation Data Center, Guangzhou, China

2. Funding information was missing in the original version. The funding information is shown below.

Funding information

This research was supported in part by the Scientific and Technological Collaborative Innovation System Project of Social Development of Guangdong Province (No. 2018B020207012), the National Key R\&D Program of China (No. 2018YFB1004600) and the National Science and Technology Major Project (No. 2017ZX05036-001-010). The original article has been corrected.

Publisher's note Springer Nature remains neutral with regard to jurisdictional claims in published maps and institutional affiliations.

The online version of the original article can be found at https://doi.org/ 10.1007/s10596-021-10080-Z

Yuyao Ci

cindy.ci@cug.edu.cn

1 School of Geography and Information Engineering, China University of Geosciences, Wuhan, China

2 Guangdong Meteorological Observation Data Center, Guangzhou, China 